I.

\title{
ANALISA RESETTING OVER CURRENT RELAY DAN GROUND FAULT RELAY PADA TRAFO 60 MVA 150/20 kV DAN PENYULANG 20 kV GARDU INDUK PADANG SAMBIAN
}

\author{
Indra Gunawan ${ }^{1}$, Wayan Rinas ${ }^{2}$, I Gusti Ngurah Janardana ${ }^{3}$ \\ Program Studi Teknik Elektro, Fakultas Teknik Universitas Udayana \\ Email: indragunawan596@gmail.comi ${ }^{\underline{1}}$, rinas@unud.ac.id ${ }^{2}$, janardana@unud.ac.id ${ }^{3}$
}

\begin{abstract}
Abstrak
Kebutuhan energi listrik di Bali mengalami peningkatan pertahunnya sebesar 135,2 GWh, sehingga Perusahaan Listrik Negara (PLN) dituntut untuk menambah pusat-pusat pembangkit baru atau penambahan trafo untuk melayani beban disisi penyulang. Gardu Induk Padang Sambian telah dilakukan penambahan trafo baru dan penyulang Padang Sambian direkonfigurasi. Rekonfigurasi penyulang menyebabkan nilai impedansi penyulang berubah, sehingga berpengaruh terhadap setting sistem proteksi seperti Over Current Relay (OCR) dan Ground Fault Relay (GFR). Perhitungan penyetelan arus maupun waktu kerja relay OCR dan GFR dapat meminimalisir gangguan yang terjadi. Besarnya arus hubung singkat yang terjadi pada penyulang Padang Sambian dihitung untuk menentukan nilai setting relay. Hasil analisis didapatkan nilai setting arus OCR pada sisi incoming sebesar 0,91 A dengan Time Multiplier Setting (TMS) adalah 0,2 SI dan OCR pada sisi outgoing sebesar 2,063 A dengan TMS adalah 0,161 SI. Nilai setting arus untuk GFR pada sisi incoming sebesar 0,01 A dengan TMS adalah 0,27 SI dan nilai setting arus GFR pada sisi outgoing sebesar 0,16 A dengan TMS adalah 0,106 SI. Hasil dari simulasi Electrical Power System Analysis (ETAP) didapatkan kurva koordinasi OCR dan GFR karakteristik arus terhadap waktu atau Time-Curve Current (TCC) tidak berpotongan. Hal tersebut menunjukkan bahwa koordinasi berjalan baik dan memenuhi persyaratan sensifitas, keandalan, selektivitas dan kecepatan.
\end{abstract}

Kata Kunci: Setting, Relay, Penyulang, Rekonfigurasi.

\begin{abstract}
Electricity energy needs in Bali have increased annually by 135,2 GWh, as a result, the State-Owned Electrcity Company (PLN) is being required to add new power plants or the addition of transformer to serve load side fedeers. New transformer have been added to Padang Sambian substation and the reconfiguration of Padang Sambian feeders. The reconfiguration causes the feeder impedance value to change, thus affecting the protection system such as Over Current Relay (OCR) and Ground Fault Relay (GFR). Calculation of current setting and OCR and GFR relay work time can minimize the interference that occurs. The amount of short circuit current that occurs in Padang Sambian fedeers was calculated to determine the value of relay settings. The result of the analysis showed that the OCR current setting value for the incoming side of 0,91 A with Time Multiplier Setting (TMS) was 0,2 SI and OCR on the outgoing side of 2,063 A with TMS of 0,161 SI. The value of current setting for the incoming GFR was 0,01 A with TMS of 0,27 SI and the setting value of the GFR current on the outgoing side was 0,16 A with TMS of 0,106 SI. The result of Electrical Power System Analysis (ETAP) simulation obtained an OCR and GFR coordination curve that did not intersect the Time-Curve Current (TCC) characteristic. This shows that coordination runs well and meets sensitivity, reliability, selectivity and speed requirements..
\end{abstract}

Keyword: Setting, Relay, Feeder, Reconfiguration.

\section{PENDAHULUAN}

Kebutuhan energi listrik di Bali pada sek-

tor rumah tangga mengalami rata-rata peningkatan pertahun sebesar 55,71 GWh, sektor komersial sebesar 73,39 GWh, sektor publik sebesar 5,64 GWh dan sektor industri 
sebesar 0,46 GWh [1]. Besarnya penigkatan kebtuhan energi listrik PLN dituntut untuk menambah pusat-pusat pembangkit baru atau penambahan trafo yang dapat melayani kebutuhan beban disisi penyulang.

Pada Gardu Induk Padang Sambian dilakukan penambahan trafo baru yang dapat melayani kebutuhan beban disisi penyulang, sehingga menyebabkan rekonfigurasi penyulang Padang Sambian dan berdampak pada berubahnya nilai impedansi penyulang, sehingga mempengaruhi nilai setting sistem proteksi, seperti Over Current Relay (OCR) dan Ground Fault Relay (GFR). Diperlukan penyetelan relay yang sangat akurat agar relay dapat memproteksi peralatan peralatan Isitrik yang lain dari arus hubung singkat maupun beban lebih. Besarnya arus hubung singkat yang terjadi pada penyulang Padang Sambian yang disimulasikan terjadi pada presentase panjang penyulang $0 \%$ $100 \%$ digunakan untuk menghitung nilai settting relay.

\section{KAJIAN PUSTAKA}

A. Perhitungan Arus Gangguan Hubung Singkat

Gangguan hubung singkat yang mungkin terjadi dalam sistem kelistrikan [2]:

a. Gangguan hubung singkat 3 fasa

b. Gangguan hubung singkat 2 fasa

c. Gangguan hubung singkat 1 fasa ketanah

Persamaan yang digunakan untuk menghitung arus gangguan hubung singkat 3 fasa, 2 fasa, dan 1 fasa ketanah [3].

a. Gangguan hubung singkat 3 fasa:

$$
I_{3 \emptyset(20)}=\frac{V_{p}}{Z_{1 e q}}
$$

b. Gangguan hubung singkat 2 fasa:

$$
I_{2 \emptyset(20)}=\frac{V_{p}}{Z_{1 e q}+Z_{2 e q}}
$$

c. Gangguan hubung singkat 1 fasa ketanah:

$$
I_{1 \varnothing(20)}=\frac{3 \times V_{p}}{Z_{1 e q}+Z_{2 e q}+Z_{3 e q}}
$$

Keterangan:

$I_{3 \varnothing(20)}$ adalah Arus hubung singkat 3 fasa di sisi $20 \mathrm{kV}(A)$
$I_{2 \varnothing(20)} \begin{aligned} & \text { adalah arus hubung singkat } 2 \\ & \text { fasa di sisi } 20 \mathrm{kV}(A)\end{aligned}$
$I_{1 \varnothing(20)} \begin{aligned} & \text { adalah arus hubung singkat } 1 \text { fasa } \\ & \text { ke tanah disisi } 20 \mathrm{kV}(A)\end{aligned}$
$Z_{e q 1} \begin{aligned} & \text { adalah impedansi ekivalen penyu- } \\ & \text { lang urutan positif }(\mathrm{Ohm})\end{aligned}$
$Z_{e q 2} \begin{aligned} & \text { adalah impedansi ekivalen penyu- } \\ & \text { lang urutan negatif (Ohm) }\end{aligned}$
$Z_{e q 3} \begin{aligned} & \text { adalah impedansi ekivalen penyu- } \\ & \text { lang urutan nol (Ohm) }\end{aligned}$
$V_{p} \quad \begin{aligned} & \text { adalah tegangan nominal sistem } \\ & 20 \mathrm{kV}(\mathrm{V})\end{aligned}$

Perhitungan Impedansi sumber dengan Persamaan (5), impedansi trafo dengan persamaan (6) dan impedansi penyulang dengan Persamaan (9) (10) dilakukan untuk mendapatkan besarnya arus gangguan hubung singkat yang terjadi pada penyulang [4].

1. Impedansi Sumber:

$$
\begin{gathered}
Z_{s 150 k V}=\frac{k V_{p}^{2}}{M V A_{h s}} \\
Z_{s 20 k V}=\frac{k V_{s}^{2}}{k V_{p}^{2}} \times Z_{s 150 k V}
\end{gathered}
$$

Keterangan:

$k V_{s} \quad$ adalah tegangan sisi sekunder (V) $k V_{p} \quad$ adalah tegangan sisi primer ( $V$ ) $Z_{\text {s150kV }}$ adalah impedansi sumber $(\mathrm{Ohm})$ $Z_{\text {s20kV }}$ adalah Impedansi sisi $20 \mathrm{kV}$ $(\mathrm{Ohm})$

2. Impedansi trafo:

$$
Z_{t r}=\frac{V_{s}^{2} Z_{t}}{\frac{s}{1000}}
$$

Keterangan:

$V_{s}$ adalah tegangan nominal sisi sekunder ( $V$ )

$S$ adalah daya trafo (VA)

$Z_{t}$ adalah impedansi $(\mathrm{Ohm})$

$Z_{t r}$ adalah mpedansi sisi trafo $(\mathrm{Ohm})$

3. Impedansi penyulang

Pada perhitungan impedansi penyulang dihitung impedansi urutan positif, negatif dan nol, sebagai berikut:

a. Impedansi penyulang urutan positif dan negatif

$$
\begin{aligned}
& Z_{1}=\text { Panjang penyulang } x Z_{p 1} \\
& Z_{1}=Z_{2}
\end{aligned}
$$

b. Impedansi penyulang urutan nol

$$
Z_{0}=\text { Panjang penyulang } \times Z_{p 0}
$$


I.

c. Impedansi ekivalen jaringan urutan positif dan negatif

$$
\begin{gathered}
Z_{\text {1eq }}=Z_{\text {sumber }}+Z_{1 T}+Z_{1 \text { penyulang }} \\
Z_{\text {1eq }}=Z_{\text {2eq }}
\end{gathered}
$$

d. Impedansi ekivalen jaringan urutan nol

$$
Z_{\text {oeq }}=Z_{O T}+3 R_{N}+Z_{\text {openyulang }}
$$

Keterangan:

$Z_{1}$ adalah impedansi urutan positif (Ohm)

$Z_{2}$ adalah impedansi urutan negatif (Ohm)

$Z_{0} \quad$ adalah impedansi urutan nol (Ohm)

$Z_{1 T}$ adalah impedansi urutan positif trafo $(\mathrm{Ohm})$

$Z_{\text {OT }}$ adalah impedansi urutan nol trafo (Ohm)

$Z_{\text {leq }}$ adalah impedansi ekivalen jaringan urutan positif $(\mathrm{Ohm})$

$Z_{\text {2eq }}$ adalah impedansi ekivalen jaringan urutan negatif $(\mathrm{Ohm})$

$Z_{\text {oeq }}$ adalah impedansi ekivalen jaringan urutan nol (Ohm)

$R_{N}$ adalah resistansi (Ohm)

$Z_{\text {1penyulang }}$ adalah impedansi urutan positif penyulang (Ohm)

$Z_{\text {openyulang }}$ adalah mpedansi urutan nol penyulang $(\mathrm{Ohm})$

$Z_{\text {sumber }}$ adalah mpedansi Sumber (Ohm)

\section{B. Over Current Relay (OCR)}

OCR mendeteksi adanya hubung singkat antar fasa yang berada dalam wilayah proteksinya serta merupakan proteksi cadangan pada transformator daya [5]. OCR tidak boleh bekerja pada keadaan beban maksimum. Arus nominal dari current transformer merupakan arus maksimumnya sehingga penyetelan arusnya adalah [6]:

$$
\begin{aligned}
& I_{\text {setP }}=1,05 \times I_{\text {nominal trafo }} \\
& I_{\text {setS }}=I_{\text {serP }} \times 1 / \text { Rasio CT }
\end{aligned}
$$

Keterangan :

$I_{\text {setP }}$ adalah setelan arus primer $(A)$

$I_{\text {sets }}$ adalah etelan arus sekunder $(A)$

Rasio CT adalah rasio transformator arus $(A)$

$I_{\text {nominal trafo }}$ adalah arus nominal trafo $(A)$

Hasil perhitungan arus gangguan hubung singkat, selanjutnya digunakan untuk menentukan nilai setelan waktu (TMS). Berikut adalah persamaan untuk menghitung TMS [6] :

$$
t=\frac{\alpha \times T M S}{\left[\frac{I_{\text {fault }}}{I_{\text {set }}}\right]^{\beta}-1}
$$

\section{Keterangan:}

TMS adalah time multiple setting

$t \quad$ adalah waktu kerja relay $(s)$

$I_{\text {fault }}$ adalah arus gangguan $(A)$

$\alpha \beta$ adalah konstanta jenis karakteristik relay standart inverse

\section{Ground Fault Relay (GFR)}

GFR pada dasarnya memiliki prinsip kerja yang sama dengan OCR. GFR digunakan untuk mendeteksi adanya hubung singkat satu fasa ke tanah. Berikut adalah persamaan untuk menghitung setting arus GFR pada sisi primer [6]:

$$
I_{\text {SetP }}=6 \% \mathrm{~s} / \mathrm{d} 12 \% \times I_{\text {hs terkecil }}
$$

Berikut adalah persamaan untuk menghitung setting arus GFR pada sisi sekunder [6]:

$$
I_{\text {sets }}=\frac{I_{\text {setp }}}{\text { Rasio } C T}
$$

Keterangan:

$I_{\text {setP }}$ adalah setelan arus primer (A)

$I_{\text {sets }}$ adalah setelan arus sekunder (A)

Rasio CT adalah rasio transformator arus (A)

$I_{\text {hs terkecil adalah Arus Hubung singkat }}$ terkecil

Pada penyetelan relay TMS GFR sisi incoming dan outgoing, arus gangguan yang digunakan adalah arus hubung singkat 1 fasa ketanah. Perhitungan TMS relay GFR menggunakan Persamaan (13).

\section{METODE PENELITIAN}

Metode penelitian yang digunakan dalam analisis penelitian ini dapat dilihat pada bagan berikut ini: 


\section{I.}

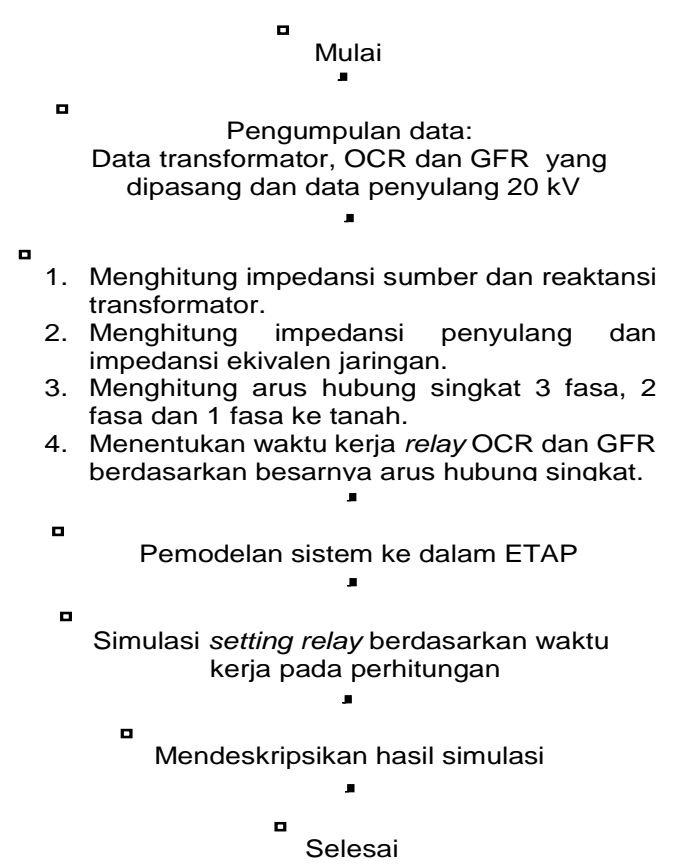

Gambar 1. Bagan alur penelitian

\section{HASIL ANALISIS DAN PEMBAHASAN}

A. Perhitungan Arus Hubung Singkat

Impedansi sumber $150 \mathrm{kV}$ dihitung dari Persamaan (4):

$$
\begin{aligned}
Z_{150 k V} & =\frac{150^{2}}{3022.34} \\
& =7.44 \mathrm{Ohm}
\end{aligned}
$$

Impedansi sumber $20 \mathrm{kV}$ dihhitung dari Persamaan (5):

$$
\begin{aligned}
Z_{s 20 k V} & =\frac{20^{2}}{150^{2}} \times 7,44 \\
& =0,132 \mathrm{Ohm}
\end{aligned}
$$

Reaktansi trafo dihitung dari Persamaan (6):

$$
\begin{aligned}
Z_{t r} & =\frac{20^{2} \times 11,9 \%}{60} \\
& =0,793 \mathrm{ohm}
\end{aligned}
$$

Impedansi penyulang Padang Sambian urutan positif dan negatif dihitung dari Persamaan (7):

$$
\begin{aligned}
& Z_{\text {1penyulang }}=Z_{\text {2penyulang }} \\
& =2,4148+j 3,6949+1,3657+j 0,5547 \\
& =2,7805+j 4,2496 \text { Ohm }
\end{aligned}
$$

Impedansi penyulang Padang Sambian urutan nol dihitung dari Persamaan (8):

$$
\begin{aligned}
\mathrm{Z}_{0 \text { Penyulang }} & =4,0583+\mathrm{j} 18,089+1,0972+ \\
\mathrm{j} 1,386 & =5,1555+\mathrm{j} 19,4752 \mathrm{Ohm}
\end{aligned}
$$

Impedansi ekivalen jaringan urutan positif dan negatif diansumsikan gangguan terjadi di presentase panjang penyulang $5 \%$, dihitung dari Persamaan (9):

$$
\begin{aligned}
& Z_{1 \text { eq }}=Z_{\text {2eq }} \\
& Z_{1 \text { eq }}=j 0,312+j 0,793+0,139+j 0,212 \\
& \quad=0,139+j 1,137 \text { Ohm }
\end{aligned}
$$

Impedansi ekivalen jaringan urutan nol diansumsikan gangguan di presentase panjang penyulang 5\%, dihitung dari Persamaan (10):

$$
\begin{aligned}
& Z_{0 \text { eq }}=j 7,93+3 \times 40+0,258+j 0,974 \\
& \quad=120,258+j 8,9040 h m
\end{aligned}
$$

Arus gangguan hubung singkat 3 fasa diansumsikan terjadi di presentase panjang penyulang 5\%, dihitung dari Persamaan (1):

$$
\begin{aligned}
I_{3 \emptyset(20)} & =\frac{\frac{20000}{\sqrt{3}}}{0,139+j 1.137} \\
& =\frac{11,547}{0,139+j 1,137} \\
& =\frac{11,547}{\sqrt{0,139^{2}+1,137^{2}}} \\
& =10070,27 \mathrm{~A}
\end{aligned}
$$

Arus gangguan hubung singkat 2 fasa diansumsikan terjadi di presentase panjang penyulang $5 \%$, dihitung dari Persamaan (2):

$$
\begin{aligned}
I_{2 \emptyset(20)} & =\frac{20000}{2 x(0,139+j 1,137} \\
& =\frac{20000}{0,278+j 2,274} \\
& =\frac{20000}{\sqrt{0,278^{2}+2,274^{2}}}
\end{aligned}
$$




\section{I.}

$$
=8721,11 \mathrm{~A}
$$

Arus gangguan hubung singkat 1 fasa ketanah di ansumsikan terjadi di presentase panjang penyulang $5 \%$, dihitung dari Persamaan (3):

$$
\begin{aligned}
I_{1 \varnothing(20)} & =\frac{\frac{3 \times 20000}{\sqrt{3}}}{2 x(0,139+j 1,137)+120,258+j 8,904} \\
& =\frac{34641,016}{120,536+j 11,178} \\
& =\frac{34641,016}{\sqrt{120,536^{2}+11,178^{2}}} \\
& =286,16 \mathrm{~A}
\end{aligned}
$$

Hasil perhitungan arus gangguan hubung singkat 3 fasa, 2 fasa dan 1 fasa ke tanah yang telah didapat, digunakan untuk perhitungan penyetelan relay OCR dan relay GFR pada sisi outgoing dan sisi incoming. Berikut diperlihatkan secara lengkap hasil perhitungan arus hubung singkat 3 fasa, 2

\begin{tabular}{|c|c|c|c|}
\hline $\begin{array}{c}\text { Presentase } \\
\text { Panjang } \\
\text { Penyulang } \\
(\%)\end{array}$ & $\begin{array}{c}I_{\text {f3tasa }} \\
(A)\end{array}$ & $\begin{array}{c}I_{\text {f2fasa }} \\
(A)\end{array}$ & $\begin{array}{c}I_{\text {f1fasa }} \\
(A)\end{array}$ \\
\hline 0 & 12474,07 & 10802,86 & 287,72 \\
\hline 5 & 10070,27 & 8721,11 & 286,16 \\
\hline 10 & 8373,29 & 7251,49 & 284,59 \\
\hline 15 & 7136,94 & 6180,77 & 282,99 \\
\hline 20 & 6205,34 & 5373,98 & 281,39 \\
\hline 25 & 5482,04 & 4747,58 & 279,76 \\
\hline 30 & 4906,00 & 4248,72 & 278,13 \\
\hline 35 & 4437,31 & 3842,82 & 276,48 \\
\hline 40 & 4049,02 & 3506,55 & 274,83 \\
\hline 45 & 3722,35 & 3223,65 & 273,16 \\
\hline 50 & 3443,88 & 2982,48 & 271,49 \\
\hline 55 & 3203,78 & 2774,55 & 269,81 \\
\hline 60 & 2994,70 & 2593,48 & 268,13 \\
\hline 65 & 2811,04 & 2434,43 & 266,44 \\
\hline 70 & 2648,46 & 2293,63 & 264,75 \\
\hline 75 & 2503,54 & 2168,13 & 263,06 \\
\hline
\end{tabular}
fasa dan 1 fasa ke tanah yang diansumsikan terjadi ditiap kelipatan 5\% panjang penyulang.

Tabel 1. Arus Hubung Singkat 3 Fasa, 2 Fasa dan 1 Fasa Ke Tanah Hasil Perhitungan

\begin{tabular}{|c|l|l|l|}
\hline 80 & 2373,59 & 2055,58 & 261,36 \\
\hline 85 & 2256,39 & 1954,09 & 259,67 \\
\hline 90 & 2150,17 & 1862,10 & 257,97 \\
\hline 95 & 2053,46 & 1778,35 & 256,28 \\
\hline 100 & 1965,05 & 1701,78 & 254,59 \\
\hline
\end{tabular}

Pada Tabel 1 dapat dilihat bahwa arus hubung singkat terbesar yang timbul pada gangguan hubung singkat 3 fasa, 2 fasa maupun 1 fasa ketanah terjadi pada presentase panjang penyulang $0 \%$ atau pangkal penyulang, sedangkan terkecil pada presentase panjang penyulang $100 \%$ atau ujung penyulang. Nilai dari impedansi sistem mempengaruhi arus hubung singkat.

\section{B. Setting OCR dan GFR}

Pada penyetelan relay OCR sisi incoming $20 \mathrm{kV}$ ada dua jenis nilai setting yang akan dihitung, nilai setting arus dan nilai time multiplier setting (TMS) relay.

1. Setting OCR sisi incoming $20 \mathrm{kV}$

Setting arus OCR dihitung dari Persamaan (11):

$$
\begin{aligned}
I_{\text {set sekunder }} & =1816,6 \times \frac{1}{2000} \\
& =0,91 \mathrm{~A}
\end{aligned}
$$

Setting TMS OCR dihitung dari Persamaan (13):

$$
\begin{aligned}
0,7 & =\frac{0,14 \times t m s}{\left[\frac{12474.07}{1818,6}\right]^{0,02}-1} \\
\mathrm{Tms} & =0,2 \mathrm{SI}
\end{aligned}
$$

2. Setting GFR sisi Incoming $20 \mathrm{kV}$

Setting arus GFR dihitung dari Persamaan (15):

$$
\begin{aligned}
I_{\text {set sekunder }} & =\frac{20,36}{1 / 2000} \\
& =0,01 \mathrm{~A}
\end{aligned}
$$

Setting TMS GFR dihitung dari Persamaan (13):

$$
\begin{aligned}
0,7 & =\frac{0,14 \times \text { tms }}{\left[\frac{287,72}{20,36}\right]^{0,02}-1} \\
\operatorname{Tms} & =0,27 \mathrm{SI}
\end{aligned}
$$


I.

3. Setting OCR sisi outgoing $20 \mathrm{kV}$

Setting arus OCR dihitung dari Persamaan (11) :

$$
\begin{aligned}
I_{\text {set sekunder }} & =330,008 \times \frac{1}{800 / 5} \\
& =2,063 \mathrm{~A}
\end{aligned}
$$

Setting TMS OCR dihitung dari Persamaan (11):

$$
\begin{aligned}
0,3 & =\frac{0,14 \times t m s}{\left[\frac{12474,07}{330,088}\right]^{0,02}-1} \\
\mathrm{Tms} & =0,161 \mathrm{SI}
\end{aligned}
$$

4. Setting GFR sisi outgoing $20 \mathrm{kV}$ Settinig arus GFR dihitung dari Persaman (15):

$$
\begin{aligned}
I_{\text {set sekunder }} & =25,46 \times \frac{1}{800 / 5} \\
& =0,16 \mathrm{~A}
\end{aligned}
$$

Setting TMS GFR dihitung dari Persamaan (13):

$$
0,3=\frac{0,14 \times t m s}{\left[\frac{287,72}{25,46}\right]^{0,02}-1}
$$

\begin{tabular}{|c|c|c|}
\hline Relay & \multicolumn{2}{|c|}{ Hasil Perhitungan } \\
\hline \multirow{3}{*}{$\begin{array}{c}\text { OCR } \\
\text { (incoming) }\end{array}$} & TMS (SI) & 0,2 \\
\hline & $\mathrm{t}(\mathrm{s})$ & 0,7 \\
\hline & I set $(A)$ & 0,91 \\
\hline \multirow{3}{*}{$\begin{array}{c}\text { GFR } \\
\text { (incoming) }\end{array}$} & TMS (SI) & 0,27 \\
\hline & $\mathrm{t}(\mathrm{s})$ & 0,7 \\
\hline & I set $(A)$ & 0,01 \\
\hline \multirow{3}{*}{$\begin{array}{c}\text { OCR } \\
\text { (Outgoing) }\end{array}$} & TMS (SI) & 0,161 \\
\hline & $\mathrm{t}(\mathrm{s})$ & 0,3 \\
\hline & I set $(A)$ & 2,063 \\
\hline \multirow{3}{*}{$\begin{array}{c}\text { GFR } \\
\text { (Outgoing) }\end{array}$} & TMS (SI) & 0,106 \\
\hline & $\mathrm{t}(\mathrm{s})$ & 0,3 \\
\hline & I set $(A)$ & 0,16 \\
\hline
\end{tabular}

Tms $=0,106 \mathrm{SI}$

Hasil perhitungan setting relay OCR dan relay GFR dengan setting standar inverse time diperlihatkan pada Tabel 2.

.Tabel 2. Hasil perhitungan setting OCR dan GFR

Dari hasil perhitungan setting OCR dan GFR yang terdapat pada Tabel 2, dapat dilakukan simulasi koordinasi relay dengan menggunakan star-protective device coordination pada ETAP software. Setelah semua hasil setting diatas dimasukan kedalam ETAP, maka simulasi sudah bisa dijalankan dan menghasilakan kurva koordinasi relay karakteristik arus terhadap waktu (TCC) seperti pada Gambar 2 dan Gambar 3 berikut ini:

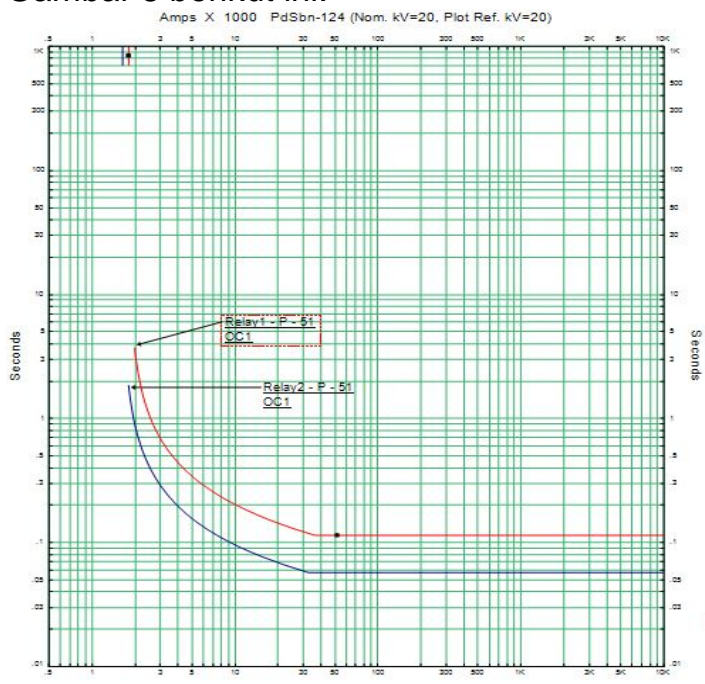

Gambar 2. Kurva Koordinasi OCR Karakteristik Arus Terhadap Waktu (TCC)

Pada Gambar 2 dapat dilihat bahwa kurva warna merah menunjukkan OCR pada sisi incoming dan kurva warna biru menunjukkan OCR pada sisi outgoing. Pada simulasi diberikan arus gangguan hubung singkat 3 fasa pada penyulang sehingga dapat dilihat pada kurva kooordinasi karakteristik waktu terhadap arus (time curve current) yang akan terlebih dahulu bekerja adalah OCR sisi outgoing dibandingkan OCR di sisi incoming. Hal tersebut menunjukkan bahwa setting koordinasi relay OCR telah berjalan dengan bailk sesuia dengan standar kepekaan, kecepatan dan selektifitas relay. 


\section{I.}

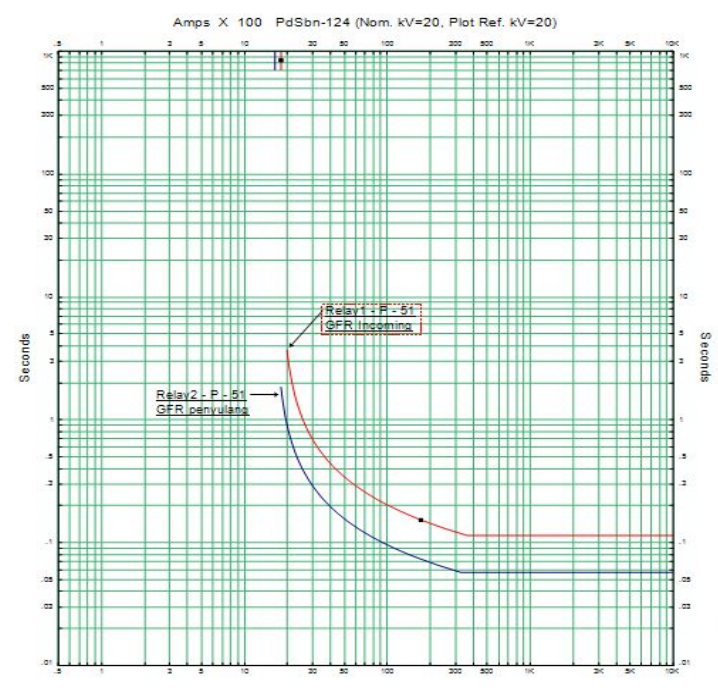

Gambar 3. Kurva Koordinasi GFR Karakteristik Arus Terhadap Waktu (TCC)

Pada Gambar 3 dapat dilihat bahwa kurva warna merah menunjukkan GFR pada sisi incoming dan kurva warna biru menunjukkan GFR pada sisi outgoing. Pada simulasi diberikan gangguan 1 fasa ke tanah pada penyulang sehingga dapat dilihat pada kurva koordinasi karakteristik waktu terhadap arus (time curve current) yang akan terlebih dahulu bekerja adalah GFR sisi outgoing (biru) dibandingkan GFR sisi incoming (merah).

Hal tersebut menunjukkan bahwa setting koordinasi relay GFR telah berjalan dengan baik sesuai dengan standar kepekaan, kecepatan dan selektivitas relay.

\section{SIMPULAN}

Berdasarkan hasil analisis yang telah dilakukan, maka dapat disimpulkan bahwa nilai setting arus OCR pada sisi incoming sebesar 1818,6 A (primer) / 0,91 A (sekunder) dan OCR pada sisi outgoing sebesar 330,088 A (primer) / 2,063 A (sekunder). Nilai setting arus untuk GFR pada sisi incoming sebesar 20,36 A (primer) / 0,01 A (sekunder) dan nilai setting arus untuk GFR pada sisi outgoing sebesar 25,46 A (primer) / 0,16 A (sekunder). Penyetelan OCR pada sisi incoming didapat nilai TMS sebesar 0,2 SI dan OCR. Pada sisi outgoing TMS sebesar 0,161 SI. Penyetelan GFR pada sisi incoming didapat nilai TMS sebesar 0,27 SI dan GFR pada sisi outgoing didapat nilai TMS sebesar 0,106 SI. Waktu kerja relay pada sisi outgoing lebih cepat dibandingkan dengan waktu kerja relay sisi incoming karena relay sisi incoming berfungsi sebagai back up dari relay pada sisi outgoing sehingga bisa mengamankan gangguan di sisi penyulang.

\section{DAFTAR PUSTAKA}

[1] Satya, U.N.P., Prakiraan Kebutuhan Tenaga Listrik Propinsi Bali Sampai Tahun 2018 Dengan Metode Regresi Berganda Deret Waktu. Teknologi Elektro. 2007; 6(1)

[2] Hermansyah. MT. Rasiman. Analisa Arus Gangguan Hubung Singkat Pada Incoming $20 \mathrm{kV}$ Transformator 3 Gardu Induk Cibinong. Bogor: Universitas Ibn Khaldun Bogor. 2011.

[3] Stevenson, Jr William D, Analisis Sistem Tenaga Listrik, Edisi keempat, Jakarta Pusat: Erlangga, 1984.

[4] Saadat, Hadi, Power System Analysis, Singapore: Mc. Graw Hill Book Company. 1999.

[5] PT. PLN (Persero). Proteksi dan Kontrol Transformator. Kebayoran Baru, Jakarta: .2014

[6] PT. PLN (Persero) APD Bali. Proteksi PLN APD Bali. Denpasar: 2015 